\title{
THE EFFECT OF BARBITURATES IN PATIENTS WITH LIVER DISEASE ${ }^{1}$
}

\author{
By JOHN T. SESSIONS, JR.,2 HERBERT P. MINKEL, JOHN C. BULLARD, AND
}

FRANZ J. INGELFINGER

\begin{abstract}
(From the Evans Memorial, Massachusetts Memorial Hospitals, the Boston Veterans Administration Hospital and the Department of Medicine, Boston University School of Medicine, Boston, Mass.)
\end{abstract}

(Submitted for publication May 27, 1952; accepted March 22, 1954)

Although sedatives are frequently required in the treatment of patients with liver disease, barbiturates are believed to be contraindicated in the face of impaired hepatic function. Three points are advanced in support of this belief: First, patients with advanced liver disease have remained comatose for long periods of time after receiving a barbiturate; second, animals after chloroform induced hepatic damage or partial liver extirpation have shown an increased sensitivity to anesthetic doses of barbiturates $(1,2)$; and third, animals are alleged to show a greater than normal retention of pentobarbital and barbital in their blood and tissues after chloroform anesthesia (3). These points of evidence, however, are far from conclusive. The natural progression of hepatic coma from a stage of restlessness to one of somnolence, and the spontaneous fluctuations that occur in the course of liver disease reduce the significance of temporal correlations in determining the part any single factor plays in causing hepatic coma. As far as animal experiments are concerned, they are not necessarily applicable to man, particularly if the type of liver damage and the barbiturate dosage are not comparable to the usual clinical situation. Finally, methods of barbiturate analysis are difficult and non-specific. Since the evidence incriminating the use of barbiturates in liver disease seemed circumstantial, a study to obtain direct evidence was undertaken. Three questions in particular seemed worthy of consideration:

\footnotetext{
1 The work reported herein was supported by a contract from the Veterans Administration upon recommendation of the National Research Council's Committee on Veterans Medical Problems.

2 Present address : Department of Medicine, University of North Carolina, Chapel Hill, N. C.
}

1. Do barbiturates damage the liver itself?

2. Are patients with liver disease more sensitive to barbiturates because of impaired inactivation of these drugs by the damaged liver?

3. Are patients with liver disease more sensitive to barbiturates because of increased sensitivity of the nervous system?

Information bearing on these questions was sought by comparing the effect of barbiturates in control subjects and patients with liver disease. Pentobarbital (Nembutal ${ }^{\circledR}$ ) was the barbiturate principally used because it is a popular drug and is said to be inactivated by the liver. The effects of both single doses and prolonged administration of barbiturate were observed.

\section{EFFECTS OF SINGLE DOSES OF BARBITURATE}

\section{Material and methods.}

Pentobarbital was given to 35 control subjects without liver or central nervous system disease and to 21 patients with liver disease. As indicated in Table I, all of these patients except one had signs and symptoms of advanced hepatic damage. Seventeen of these patients had cirrhosis with an alcoholic background but at the time of the acute studies were suffering neither from alcoholism nor its withdrawal symptoms. After preliminary studies showed that oral doses were well tolerated, intravenous administration (sodium pentobarbital) was used routinely in subsequent studies to eliminate the variables of intestinal absorption and to provide a sharp beginning point for both clinical and biochemical measurements. The drug was given either as a single injection during the course of one-half minute or as a constant intravenous infusion over a 30 -minute period. Single injections were given 40 times to patients with liver disease and 35 times to control subjects. The doses varied from 30 to $240 \mathrm{mg}$., but in 75 per cent of the tests 100 to $120 \mathrm{mg}$. was used. Doses given to control and patient groups were comparable. Intravenous infusions containing 100 to $180 \mathrm{mg}$. of sodium pentobarbital in $120 \mathrm{ml}$. were given to $10 \mathrm{pa}$ tients with liver disease and to seven control subjects. 
TABLE 1

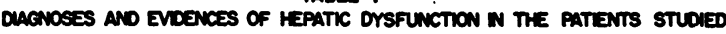

\begin{tabular}{|c|c|c|c|c|c|c|c|c|}
\hline \multicolumn{2}{|c|}{ Potiont } & Diopnowis & $\begin{array}{c}\text { Esophogeed } \\
\text { Vortices }\end{array}$ & Ascilines & Albumin & 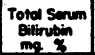 & 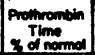 & $\begin{array}{l}\text { Formol } \\
\text { Get }\end{array}$ \\
\hline \multicolumn{9}{|c|}{ PATLENTS GNEN SANGLE DOSE OF BARETTURATE - ACUTE STLORES } \\
\hline 1 & C.R. & 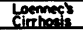 & No & res & 2.1 & 6.8 & 26 & not donen \\
\hline 2 & M.K. & $"$ & " & n & 2.7 & 10.8 & 75 & $"$ \\
\hline 3 & M.c. & " & " & ." & 2.1 & 5.7 & 30 & $"$ \\
\hline 4 & s.v. & " & " & " & 2.3 & 2.3 & 50 & " \\
\hline 5 & J.N. & $"$ & YES & $"$ & 2.5 & 1.6 & 45 & " \\
\hline 6 & E.o. & " & " & " & 2.8 & 2.5 & 30 & " \\
\hline 7 & J.C. & " & no & $"$ & 2.6 & 11.0 & 26 & $"$ \\
\hline 8 & A.M. & $"$ & not exomined & 11 & 1.1 & 25.5 & 27 & $n$ \\
\hline 9 & H.C. & $"$ & rES & $"$ & 1.9 & 1.4 & 30 & 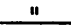 \\
\hline 10 & $F \boldsymbol{m}$ & $"$ & _" & 1 & 2.1 & 7.8 & 27 & $"$ \\
\hline II & L.F. & $"$ & $"$ & $"$ & 2.8 & 0.5 & 30 & " \\
\hline 12 & J.F. & "1 & $"$ & $\mu$ & 2.2 & 1.3 & 48 & $n$ \\
\hline 13 & M.c. & $"$ & $"$ & $"$ & 2.0 & 2.7 & 44 & $n$ \\
\hline 14 & c.s. & $"$ & no & "I & 1.7 & 2.1 & 65 & $"$ \\
\hline 15 & J.H. & $"$ & not enemined & $" 1$ & 2.0 & 2.8 & 75 & " \\
\hline (16) & w.w. & " & " & No & 2.3 & 7.0 & 37 & " \\
\hline 17 & O.H. & $"$ & no & rES & 2.8 & 1.8 & 70 & $"$ \\
\hline 18. & G.W. & Hepotomo & YES & $"$ & 2.5 & 2.8 & 69 & $"$ \\
\hline 19) & W.D. & $"$ & No & $"$ & 2.5 & 1.7 & 65 & $"$ \\
\hline 20 & $0 . T$. & cirtiong & res & in & 2.0 & 7.4 & 48 & u \\
\hline 21) & 1.L. & $\begin{array}{l}\text { Virol } \\
\text { Heditis }\end{array}$ & $\infty$ & no & 4.4 & 0.8 & 70 & " \\
\hline \multicolumn{9}{|c|}{ PATIENTS GIVEN REPEATED DOSES OF BARETURATE - PROLONGED STLOESS } \\
\hline 1 & c. & Coeprect & No & YES & not done & 3.3 & 35 & $4+$ \\
\hline 2 & a & $"$ & $"$ & $"$ & $"$ & 10.8 & 28 & 40 \\
\hline 3 & $T$. & $"$ & YES & $"$ & $"$ & 5.6 & 42 & $4+$ \\
\hline 4 & M. & $"$ & not exomined & $"$ & 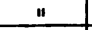 & 4.3 & 68 & 4 \\
\hline 5 & c. & $\|$ & YES & $"$ & 1 & 1.5 & 42 & 4 \\
\hline 6 & D. & $"$ & no & $"$ & $"$ & 2.0 & 45 & 4 \\
\hline 7 & c. & $"$ & no & $"$ & $"$ & 122 & 39 & 4 \\
\hline 8 & H. & $"$ & YES & $"$ & 3.0 & 4.0 & 30 & 4. \\
\hline 9 & c. & $"$ & not examined & $"$ & not done. & 0.7 & 36 & 4. \\
\hline 10$]$ & s. & 11 & 11 & $"$ & 11 & 43.0 & 61 & $4+$ \\
\hline
\end{tabular}

Evaluation of barbiturate effects was attempted by three general methods : clinical observation, liver function tests and measurement of pentobarbital blood levels. Since there are no established methods for measuring either clinical manifestations or pentobarbital blood levels that follow the intravenous injection of ordinary hypnotic doses of pentobarbital, the choice, development and adequacy of methods used by us are discussed in some detail.

\section{Clinical observations.}

When it appeared that the doses used in our study would not elicit the signs described as characteristic of acute and chronic barbiturate intoxication, a number of other neuropsychologic tests were investigated. The tests listed in Table II were performed before the barbiturate was given and at $\mathbf{5}$ to 30 minute intervals thereafter for one hour, or until all evidences of drug effect had disappeared. The most useful tests for following the effects of pentobarbital proved to be nystagmus, slurred speech, two-point discrimination and evaluation of changes in mood and levels of consciousness. Other tests were omitted when it became apparent that they were of little help in assessing barbiturate effects. The learning factor, varying effects of pentobarbital on mood, the degree of patient cooperation and differences in educational background made the interpretation of reading and mathematical tests difficult. No definite changes in temperature, pulse, respiration and blood pressure were noted in either patients or control subjects after barbiturates were given.

Intravenous administration of $60 \mathrm{mg}$. or less of sodium pentobarbital produced minimal changes, nystagmus on lateral gaze and slight variations in mood (euphoria, sense of "relaxation") being the usual effects of the drug. Barbiturate activity began within one-half minutes of injection and persisted for 15 to 30 minutes.

Larger intravenous doses of pentobarbital (100 to $180 \mathrm{mg}$.) intensified the nystagmus and changes in mood and induced other measurable effects. Nystagmus, as it increased, occurred in the vertical as well as horizontal plane and was accompanied frequently by blurred vision and occasionally by diplopia. Slurred speech or abnormally precise speech usually began in the first five minutes of the post-medication period and subsided during the following 20 minutes. Impaired two-point discrimination was found to correlate well with the over-all pentobarbital effect. Usually the threshold for two-point discrimination increased by 50 to 100 per cent after injecting the drug; this increase was maximal during the first 15 minutes and seldom persisted for more than 30 minutes.

The larger doses of pentobarbital also increased the degree of euphoria. The subjects were frequently more garrulous and likened the effect to that produced by alcohol. Within 15 minutes,

TABLE II

Clinical observations made on the effects of single doses of barbiturate

\begin{tabular}{lcc}
\hline \multicolumn{1}{c}{ Tests } & \multicolumn{2}{c}{ Times performed } \\
\cline { 2 - 3 } & $\begin{array}{c}\text { Patients } \\
\text { with liver } \\
\text { disease }\end{array}$ & $\begin{array}{c}\text { Control } \\
\text { subjects }\end{array}$ \\
\hline Nystagmus & 20 & 28 \\
Slurred speech & 15 & 28 \\
Two-point discrimination & 15 & 28 \\
Changes in mood and level of & 40 & 35 \\
consciousness & 22 & 18 \\
Deep-tendon reflexes & 29 & 16 \\
Finger to nose & 18 & 7 \\
Mathematical problems & 9 & 6 \\
Reading test & 9 & 6 \\
Corneal reflex & 9 & 6 \\
Temperature, pulse, respirations & & \\
\hline
\end{tabular}


TABLE IIIa

The effect of pentobarbital, 100-120 mg. I.V. as a single injection, on 28 control subjects

\begin{tabular}{|c|c|c|c|c|c|c|c|c|c|c|c|}
\hline \multirow{3}{*}{ Pt. } & \multirow[b]{2}{*}{ Age } & \multirow{3}{*}{ Diagnosis } & \multirow[b]{2}{*}{ Test } & \multicolumn{7}{|c|}{ Degree of drug effect- 0 to 4} & \multirow{2}{*}{$\begin{array}{l}\text { Sum } \\
\text { of } \\
\text { effect }\end{array}$} \\
\hline & & & & $\overline{\text { Dur: }}$ & ation 0 & $\begin{array}{l}\text { of drug } \\
30 \quad 4\end{array}$ & $\begin{array}{l}8 \text { effe } \\
45\end{array}$ & ect in & $\min _{75}$ & & \\
\hline & \multicolumn{10}{|c|}{ Given in $2 \mathrm{ml}$. } & \\
\hline \multirow[t]{2}{*}{ G. B. } & 74 & $\begin{array}{l}\text { Hypertensive } \\
\text { cardiovascu- } \\
\text { lar disease }\end{array}$ & $\begin{array}{l}\text { Nystagmus } \\
\text { 2-pt. discrim. } \\
\text { Slurred speech } \\
\text { Change in mood }\end{array}$ & $\begin{array}{l}0 \\
0 \\
0 \\
0\end{array}$ & $\begin{array}{l}2 \\
2 \\
3 \\
3\end{array}$ & $\begin{array}{l}2 \\
2 \\
2 \\
3\end{array}$ & $\begin{array}{l}1 \\
0 \\
0 \\
3\end{array}$ & $\begin{array}{l}\mathbf{0} \\
0 \\
0 \\
\mathbf{3}\end{array}$ & $\begin{array}{l}0 \\
0 \\
0 \\
2\end{array}$ & $\begin{array}{l}0 \\
0 \\
0 \\
1\end{array}$ & $\begin{array}{l}\mathbf{5} \\
\mathbf{4} \\
\mathbf{5} \\
\mathbf{9}\end{array}$ \\
\hline & & & & \multicolumn{7}{|c|}{ Barbiturate index } & 23 \\
\hline \multirow[t]{2}{*}{ S. M. } & 70 & $\begin{array}{l}\text { Generalized } \\
\text { arteriosclerosis }\end{array}$ & $\begin{array}{l}\text { Nystagmus } \\
\text { 2-pt. discrim. } \\
\text { Slurred speech } \\
\text { Change in mood }\end{array}$ & $\begin{array}{l}0 \\
0 \\
0 \\
0\end{array}$ & $\begin{array}{l}2 \\
2 \\
2 \\
3\end{array}$ & $\begin{array}{ll}2 & 1 \\
1 & 1 \\
2 & 1 \\
2 & 1\end{array}$ & $\begin{array}{l}1 \\
0 \\
1 \\
1\end{array}$ & $\begin{array}{l}\mathbf{0} \\
0 \\
0 \\
1\end{array}$ & $\begin{array}{l}\mathbf{0} \\
\mathbf{0} \\
\mathbf{0} \\
\mathbf{0}\end{array}$ & $\begin{array}{l}0 \\
0 \\
0 \\
0\end{array}$ & $\begin{array}{l}5 \\
4 \\
5 \\
7\end{array}$ \\
\hline & & & & \multicolumn{7}{|c|}{ Barbiturate index } & 21 \\
\hline \multirow[t]{2}{*}{ E. N. } & 42 & $\begin{array}{l}\text { Essential } \\
\text { hypertension }\end{array}$ & $\begin{array}{l}\text { Nystagmus } \\
\text { 2-pt. discrim. } \\
\text { Slurred speech } \\
\text { Change in mood }\end{array}$ & $\begin{array}{l}0 \\
0 \\
0 \\
0\end{array}$ & $\begin{array}{l}1 \\
1 \\
2 \\
1\end{array}$ & $\begin{array}{l}1 \\
0 \\
1 \\
1\end{array}$ & $\begin{array}{l}0 \\
0 \\
0 \\
1\end{array}$ & $\begin{array}{l}0 \\
0 \\
0 \\
0\end{array}$ & $\begin{array}{l}\mathbf{0} \\
0 \\
0 \\
0\end{array}$ & $\begin{array}{l}0 \\
0 \\
0 \\
0\end{array}$ & $\begin{array}{l}3 \\
2 \\
4 \\
4\end{array}$ \\
\hline & & & & \multicolumn{7}{|c|}{ Barbiturate index } & 13 \\
\hline \multirow[t]{2}{*}{ D. B. } & 59 & $\begin{array}{l}\text { Bronchial } \\
\text { asthma }\end{array}$ & $\begin{array}{l}\text { Nystagmus } \\
\text { 2-pt. discrim. } \\
\text { Slurred speech } \\
\text { Change in mood }\end{array}$ & $\begin{array}{l}0 \\
0 \\
0 \\
0\end{array}$ & $\begin{array}{l}2 \\
0 \\
1 \\
2\end{array}$ & $\begin{array}{l}1 \\
0 \\
0 \\
1\end{array}$ & $\begin{array}{l}0 \\
0 \\
0 \\
1\end{array}$ & $\begin{array}{l}\mathbf{0} \\
\mathbf{0} \\
\mathbf{0} \\
\mathbf{0}\end{array}$ & $\begin{array}{l}0 \\
0 \\
0 \\
0\end{array}$ & $\begin{array}{l}\mathbf{0} \\
\mathbf{0} \\
\mathbf{0} \\
\mathbf{0}\end{array}$ & $\begin{array}{l}4 \\
0 \\
2 \\
5\end{array}$ \\
\hline & & & & \multicolumn{7}{|c|}{ Barbiturate index } & 11 \\
\hline \multirow[t]{2}{*}{ F. C. } & 19 & $\begin{array}{l}\text { Duodenal } \\
\text { ulcer }\end{array}$ & $\begin{array}{l}\text { Nystagmus } \\
\text { 2-pt. discrim. } \\
\text { Slurred speech } \\
\text { Change in mood }\end{array}$ & $\begin{array}{l}0 \\
0 \\
0 \\
0\end{array}$ & $\begin{array}{l}2 \\
1 \\
0 \\
1\end{array}$ & $\begin{array}{l}1 \\
0 \\
1 \\
0\end{array}$ & $\begin{array}{l}0 \\
0 \\
0 \\
0\end{array}$ & $\begin{array}{l}0 \\
0 \\
0 \\
0\end{array}$ & $\begin{array}{l}\mathbf{0} \\
0 \\
0 \\
0\end{array}$ & $\begin{array}{l}0 \\
0 \\
0 \\
0\end{array}$ & $\begin{array}{l}4 \\
2 \\
2 \\
2 \\
\end{array}$ \\
\hline & & & & \multicolumn{7}{|c|}{ Barbiturate index } & 10 \\
\hline \multirow[t]{2}{*}{ M. M. } & 55 & $\begin{array}{l}\text { Essential } \\
\text { hypertension }\end{array}$ & $\begin{array}{l}\text { Nystagmus } \\
\text { 2-pt. discrim. } \\
\text { Slurred speech } \\
\text { Change in mood }\end{array}$ & $\begin{array}{l}0 \\
0 \\
0 \\
0\end{array}$ & $\begin{array}{l}3 \\
2 \\
1 \\
1\end{array}$ & $\begin{array}{ll}2 & 1 \\
1 & 1 \\
1 & \\
1 & \end{array}$ & $\begin{array}{l}1 \\
1 \\
0 \\
0\end{array}$ & $\begin{array}{l}0 \\
1 \\
0 \\
0\end{array}$ & $\begin{array}{l}0 \\
0 \\
0 \\
0\end{array}$ & $\begin{array}{l}0 \\
0 \\
0 \\
0\end{array}$ & $\begin{array}{l}6 \\
6 \\
3 \\
3\end{array}$ \\
\hline & & & & \multicolumn{7}{|c|}{ Barbiturate index } & 18 \\
\hline \multirow[t]{2}{*}{ E. R. } & 40 & No disease & $\begin{array}{l}\text { Nystagmus } \\
\text { 2-pt. discrim. } \\
\text { Slurred speech } \\
\text { Change in mood }\end{array}$ & $\begin{array}{l}\mathbf{0} \\
\mathbf{0} \\
0 \\
0\end{array}$ & $\begin{array}{l}2 \\
2 \\
1 \\
1\end{array}$ & $\begin{array}{ll}1 & 1 \\
1 & 0 \\
0 & 0 \\
0 & c\end{array}$ & $\begin{array}{l}1 \\
0 \\
0 \\
0\end{array}$ & $\begin{array}{l}\mathbf{0} \\
0 \\
0 \\
0\end{array}$ & $\begin{array}{l}\mathbf{0} \\
\mathbf{0} \\
\mathbf{0} \\
\mathbf{0}\end{array}$ & $\begin{array}{l}\mathbf{0} \\
\mathbf{0} \\
\mathbf{0} \\
\mathbf{0}\end{array}$ & $\begin{array}{l}5 \\
4 \\
2 \\
2\end{array}$ \\
\hline & & & & \multicolumn{7}{|c|}{ Barbiturate index } & 13 \\
\hline \multirow[t]{2}{*}{ D. C. } & 21 & $\begin{array}{l}\text { Erythema } \\
\text { nodosum }\end{array}$ & $\begin{array}{l}\text { Nystagmus } \\
\text { 2-pt. discrim. } \\
\text { Slurred speech } \\
\text { Change in mood }\end{array}$ & $\begin{array}{l}\mathbf{0} \\
\mathbf{0} \\
\mathbf{0} \\
\mathbf{0}\end{array}$ & $\begin{array}{l}2 \\
1 \\
1 \\
2\end{array}$ & $\begin{array}{ll}1 & 1 \\
0 & 0 \\
0 & 1 \\
1 & \end{array}$ & $\begin{array}{l}1 \\
0 \\
0 \\
0\end{array}$ & $\begin{array}{l}0 \\
0 \\
0 \\
0\end{array}$ & $\begin{array}{l}\mathbf{0} \\
\mathbf{0} \\
\mathbf{0} \\
\mathbf{0}\end{array}$ & $\begin{array}{l}\mathbf{0} \\
\mathbf{0} \\
\mathbf{0} \\
\mathbf{0}\end{array}$ & $\begin{array}{l}5 \\
2 \\
2 \\
4\end{array}$ \\
\hline & & & & \multicolumn{7}{|c|}{ Barbiturate index } & 13 \\
\hline \multirow[t]{2}{*}{ L. G. } & 66 & $\begin{array}{l}\text { Duodenal } \\
\text { ulcer }\end{array}$ & $\begin{array}{l}\text { Nystagmus } \\
\text { 2-pt. discrim. } \\
\text { Slurred speech } \\
\text { Change in mood }\end{array}$ & $\begin{array}{l}\mathbf{0} \\
0 \\
0 \\
0\end{array}$ & $\begin{array}{l}2 \\
0 \\
1 \\
2\end{array}$ & $\begin{array}{ll}1 & 1 \\
0 & 1 \\
0 & \\
1 & \end{array}$ & $\begin{array}{l}1 \\
0 \\
0 \\
1\end{array}$ & $\begin{array}{l}\mathbf{0} \\
\mathbf{0} \\
\mathbf{0} \\
\mathbf{0}\end{array}$ & $\begin{array}{l}0 \\
0 \\
0 \\
0\end{array}$ & $\begin{array}{l}0 \\
0 \\
0 \\
0\end{array}$ & $\begin{array}{l}5 \\
0 \\
2 \\
5\end{array}$ \\
\hline & & & & \multicolumn{7}{|c|}{ Barbiturate index } & $\overline{12}$ \\
\hline
\end{tabular}




\begin{tabular}{|c|c|c|c|c|c|c|c|c|c|c|c|}
\hline \multirow[b]{2}{*}{ Pt. } & \multirow[b]{2}{*}{ Age } & \multirow[b]{2}{*}{ Diagnosis } & \multirow[b]{2}{*}{ Test } & \multicolumn{7}{|c|}{ Degree of drug effect -0 to 4} & \multirow{2}{*}{$\begin{array}{c}\text { Sum } \\
\text { of } \\
\text { effec }\end{array}$} \\
\hline & & & & \multicolumn{7}{|c|}{$\begin{array}{l}\text { Duration of drug effect in minutes } \\
0 \quad 15 \quad 30 \quad 4560 \quad 75 \quad 90\end{array}$} & \\
\hline \multicolumn{12}{|c|}{ Given in $2 \mathrm{ml}$. } \\
\hline \multirow[t]{2}{*}{ M. H. } & 54 & $\begin{array}{l}\text { Post-chole- } \\
\text { cystectomy }\end{array}$ & $\begin{array}{l}\text { Nystagmus } \\
\text { 2-pt. discrim. } \\
\text { Slurred speech } \\
\text { Change in mood }\end{array}$ & $\begin{array}{l}\mathbf{0} \\
\mathbf{0} \\
\mathbf{0} \\
\mathbf{0}\end{array}$ & $\begin{array}{l}3 \\
0 \\
3 \\
2\end{array}$ & $\begin{array}{l}2 \\
1 \\
0 \\
1\end{array}$ & $\begin{array}{l}1 \\
0 \\
0 \\
1\end{array}$ & $\begin{array}{l}\mathbf{0} \\
\mathbf{0} \\
\mathbf{0} \\
\mathbf{0}\end{array}$ & $\begin{array}{l}0 \\
0 \\
0 \\
0\end{array}$ & $\begin{array}{l}\mathbf{0} \\
0 \\
0 \\
0\end{array}$ & $\begin{array}{l}6 \\
2 \\
4 \\
5 \\
-\end{array}$ \\
\hline & & & & \multicolumn{7}{|c|}{ Barbiturate index } & 17 \\
\hline \multirow[t]{2}{*}{ E. V. } & 58 & $\begin{array}{l}\text { Anxiety } \\
\text { state }\end{array}$ & $\begin{array}{l}\text { Nystagmus } \\
\text { 2-pt. discrim. } \\
\text { Slurred speech } \\
\text { Change in mood }\end{array}$ & $\begin{array}{l}0 \\
0 \\
0 \\
0\end{array}$ & $\begin{array}{l}1 \\
2 \\
0 \\
1\end{array}$ & $\begin{array}{l}\mathbf{0} \\
0 \\
0 \\
0\end{array}$ & $\begin{array}{l}0 \\
0 \\
0 \\
0\end{array}$ & $\begin{array}{l}\mathbf{0} \\
\mathbf{0} \\
\mathbf{0} \\
\mathbf{0}\end{array}$ & $\begin{array}{l}0 \\
0 \\
0 \\
0\end{array}$ & $\begin{array}{l}0 \\
0 \\
0 \\
0\end{array}$ & $\begin{array}{l}2 \\
3 \\
0 \\
2\end{array}$ \\
\hline & & & & \multicolumn{7}{|c|}{ Barbiturate index } & 7 \\
\hline \multirow[t]{2}{*}{ L. T. } & 27 & $\begin{array}{l}\text { Essential } \\
\text { hypertension }\end{array}$ & $\begin{array}{l}\text { Nystagmus } \\
\text { 2-pt. discrim. } \\
\text { Slurred speech } \\
\text { Change in mood }\end{array}$ & $\begin{array}{l}\mathbf{0} \\
\mathbf{0} \\
\mathbf{0} \\
\mathbf{0}\end{array}$ & $\begin{array}{l}2 \\
2 \\
1 \\
2\end{array}$ & $\begin{array}{l}1 \\
1 \\
0 \\
1\end{array}$ & $\begin{array}{l}0 \\
0 \\
0 \\
0\end{array}$ & $\begin{array}{l}\mathbf{0} \\
0 \\
0 \\
0\end{array}$ & $\begin{array}{l}\mathbf{0} \\
\mathbf{0} \\
\mathbf{0} \\
\mathbf{0}\end{array}$ & $\begin{array}{l}0 \\
0 \\
0 \\
0\end{array}$ & $\begin{array}{l}4 \\
4 \\
2 \\
4 \\
-\end{array}$ \\
\hline & & & & \multicolumn{7}{|c|}{ Barbiturate index } & 14 \\
\hline \multirow[t]{2}{*}{ A. $\mathrm{H}$. } & 64 & $\begin{array}{l}\text { Rheumatoid } \\
\text { arthritis }\end{array}$ & $\begin{array}{l}\text { Nystagmus } \\
\text { 2-pt. discrim. } \\
\text { Slurred speech } \\
\text { Change in mood }\end{array}$ & $\begin{array}{l}\mathbf{0} \\
0 \\
\mathbf{0} \\
\mathbf{0}\end{array}$ & $\begin{array}{l}3 \\
1 \\
1 \\
2\end{array}$ & $\begin{array}{l}3 \\
1 \\
0 \\
1\end{array}$ & $\begin{array}{l}2 \\
0 \\
0 \\
0\end{array}$ & $\begin{array}{l}2 \\
0 \\
0 \\
2\end{array}$ & $\begin{array}{l}0 \\
0 \\
0 \\
0\end{array}$ & $\begin{array}{l}0 \\
0 \\
0 \\
0\end{array}$ & $\begin{array}{l}7 \\
3 \\
2 \\
5\end{array}$ \\
\hline & & & & \multicolumn{7}{|c|}{ Barbiturate index } & $\overline{17}$ \\
\hline \multirow[t]{2}{*}{ C. J. } & 38 & $\begin{array}{l}\text { Pulmonary } \\
\text { infarction }\end{array}$ & $\begin{array}{l}\text { Nystagmus } \\
\text { 2-pt. discrim. } \\
\text { Slurred speech } \\
\text { Change in mood }\end{array}$ & $\begin{array}{l}\mathbf{0} \\
\mathbf{0} \\
\mathbf{0} \\
\mathbf{0}\end{array}$ & $\begin{array}{l}2 \\
2 \\
2 \\
1\end{array}$ & $\begin{array}{l}1 \\
1 \\
1 \\
1\end{array}$ & $\begin{array}{l}1 \\
0 \\
1 \\
1\end{array}$ & $\begin{array}{l}1 \\
0 \\
0 \\
0\end{array}$ & $\begin{array}{l}\mathbf{0} \\
\mathbf{0} \\
\mathbf{0} \\
\mathbf{0}\end{array}$ & $\begin{array}{l}0 \\
0 \\
0 \\
0\end{array}$ & $\begin{array}{l}6 \\
4 \\
5 \\
4\end{array}$ \\
\hline & & & & \multicolumn{7}{|c|}{ Barbiturate index } & 19 \\
\hline \multirow[t]{2}{*}{ E. B. } & 74 & Cholelithiasis & $\begin{array}{l}\text { Nystagmus } \\
\text { 2-pt. discrim. } \\
\text { Slurred speech } \\
\text { Change in mood }\end{array}$ & $\begin{array}{l}0 \\
0 \\
0 \\
0\end{array}$ & $\begin{array}{l}2 \\
2 \\
4 \\
2\end{array}$ & $\begin{array}{l}1 \\
1 \\
0 \\
1\end{array}$ & $\begin{array}{l}\mathbf{0} \\
\mathbf{0} \\
\mathbf{0} \\
\mathbf{0}\end{array}$ & $\begin{array}{l}0 \\
0 \\
0 \\
3\end{array}$ & $\begin{array}{l}0 \\
0 \\
0 \\
0\end{array}$ & $\begin{array}{l}\mathbf{0} \\
\mathbf{0} \\
\mathbf{0} \\
\mathbf{0}\end{array}$ & $\begin{array}{r}4 \\
4 \\
5 \\
6 \\
-\end{array}$ \\
\hline & & & & \multicolumn{7}{|c|}{ Barbiturate index } & 19 \\
\hline \multirow[t]{2}{*}{ R. C. } & 64 & Obesity & $\begin{array}{l}\text { Nystagmus } \\
\text { 2-pt. discrim. } \\
\text { Slurred speech } \\
\text { Change in mood }\end{array}$ & $\begin{array}{l}\mathbf{0} \\
\mathbf{0} \\
\mathbf{0} \\
\mathbf{0}\end{array}$ & $\begin{array}{l}3 \\
1 \\
1 \\
2\end{array}$ & $\begin{array}{l}2 \\
2 \\
0 \\
2\end{array}$ & $\begin{array}{l}1 \\
0 \\
0 \\
1\end{array}$ & $\begin{array}{l}0 \\
0 \\
0 \\
0\end{array}$ & $\begin{array}{l}\mathbf{0} \\
\mathbf{0} \\
\mathbf{0} \\
\mathbf{0}\end{array}$ & $\begin{array}{l}0 \\
0 \\
0 \\
0\end{array}$ & $\begin{array}{l}6 \\
4 \\
2 \\
5\end{array}$ \\
\hline & & & & \multicolumn{7}{|c|}{ Barbiturate index } & 17 \\
\hline \multirow[t]{2}{*}{ D. B. } & 40 & $\begin{array}{l}\text { Post-enceph. } \\
\text { Parkinsonism }\end{array}$ & $\begin{array}{l}\text { Nystagmus } \\
\text { 2-pt. discrim. } \\
\text { Slurred speech } \\
\text { Change in mood }\end{array}$ & $\begin{array}{l}\mathbf{0} \\
0 \\
0 \\
0\end{array}$ & $\begin{array}{l}3 \\
2 \\
2 \\
3\end{array}$ & $\begin{array}{l}2 \\
1 \\
1 \\
2\end{array}$ & $\begin{array}{l}2 \\
0 \\
0 \\
2\end{array}$ & $\begin{array}{l}2 \\
0 \\
0 \\
2\end{array}$ & $\begin{array}{l}2 \\
0 \\
0 \\
2\end{array}$ & $\begin{array}{l}2 \\
0 \\
0 \\
2\end{array}$ & $\begin{array}{l}9 \\
4 \\
4 \\
9 \\
\end{array}$ \\
\hline & & & & \multicolumn{7}{|c|}{ Barbiturate index } & 26 \\
\hline \multirow[t]{3}{*}{ M. C. } & 66 & $\begin{array}{l}\text { Generalized } \\
\text { arteriosclerosis }\end{array}$ & $\begin{array}{l}\text { Nystagmus } \\
\text { 2-pt. discrim. } \\
\text { Slurred speech } \\
\text { Change in mood }\end{array}$ & $\begin{array}{l}0 \\
0 \\
0 \\
0\end{array}$ & $\begin{array}{l}3 \\
1 \\
3 \\
3\end{array}$ & $\begin{array}{l}3 \\
1 \\
2 \\
2\end{array}$ & $\begin{array}{l}2 \\
0 \\
1 \\
2\end{array}$ & $\begin{array}{l}1 \\
0 \\
0 \\
1\end{array}$ & $\begin{array}{l}1 \\
0 \\
0 \\
0\end{array}$ & $\begin{array}{l}1 \\
0 \\
0 \\
0\end{array}$ & $\begin{array}{l}9 \\
3 \\
6 \\
7 \\
\end{array}$ \\
\hline & & & & \multicolumn{7}{|c|}{ Barbiturate index } & 25 \\
\hline & & & Given in $120 \mathrm{ml}$. infusion & & & & & & & & \\
\hline \multirow[t]{2}{*}{ W. B. } & 65 & $\begin{array}{l}\text { Duodenal } \\
\text { ulcer }\end{array}$ & $\begin{array}{l}\text { Nystagmus } \\
\text { 2-pt. discrim. } \\
\text { Slurred speech } \\
\text { Change in mood }\end{array}$ & $\begin{array}{l}\mathbf{0} \\
0 \\
\mathbf{0} \\
\mathbf{0}\end{array}$ & $\begin{array}{l}2 \\
0 \\
1 \\
0\end{array}$ & $\begin{array}{l}3 \\
1 \\
2 \\
2\end{array}$ & $\begin{array}{l}3 \\
1 \\
1 \\
3\end{array}$ & $\begin{array}{l}2 \\
0 \\
0 \\
2\end{array}$ & $\begin{array}{l}2 \\
0 \\
0 \\
1\end{array}$ & $\begin{array}{l}1 \\
0 \\
0 \\
0\end{array}$ & $\begin{array}{l}9 \\
3 \\
5 \\
7\end{array}$ \\
\hline & & & & \multicolumn{7}{|c|}{ Barbiturate index } & 24 \\
\hline
\end{tabular}




\begin{tabular}{|c|c|c|c|c|c|c|c|c|c|c|c|}
\hline \multirow{3}{*}{ Pt. } & \multirow{3}{*}{ Age } & \multirow{3}{*}{ Diagnosis } & \multirow[b]{2}{*}{ Test } & \multicolumn{7}{|c|}{ Degree of drug effect -0 to 4} & \multirow{2}{*}{$\begin{array}{c}\text { Sum } \\
\text { of } \\
\text { effect }\end{array}$} \\
\hline & & & & \multicolumn{7}{|c|}{$\begin{array}{l}\text { Duration of drug effect in minutes } \\
0 \quad 15 \quad 30 \quad 45 \quad 60\end{array}$} & \\
\hline & & & Given in $120 \mathrm{ml}$ & & & & & & & & \\
\hline \multirow[t]{2}{*}{ R. D. } & 31 & $\begin{array}{l}\text { Neurofibro- } \\
\text { matosis }\end{array}$ & $\begin{array}{l}\text { Nystagmus } \\
\text { 2-pt. discrim. } \\
\text { Slurred speech } \\
\text { Change in mood }\end{array}$ & $\begin{array}{l}0 \\
0 \\
0 \\
0\end{array}$ & $\begin{array}{l}0 \\
0 \\
0 \\
0\end{array}$ & $\begin{array}{l}2 \\
1 \\
0 \\
2\end{array}$ & $\begin{array}{l}2 \\
1 \\
0 \\
1\end{array}$ & $\begin{array}{l}1 \\
0 \\
0 \\
0\end{array}$ & $\begin{array}{l}\mathbf{0} \\
\mathbf{0} \\
\mathbf{0} \\
\mathbf{0}\end{array}$ & $\begin{array}{l}0 \\
0 \\
0 \\
0\end{array}$ & $\begin{array}{l}5 \\
3 \\
0 \\
4\end{array}$ \\
\hline & & & & \multicolumn{7}{|c|}{ Barbiturate index } & 12 \\
\hline \multirow[t]{2}{*}{ J. S. } & 28 & No disease & $\begin{array}{l}\text { Nystagmus } \\
\text { 2-pt. discrim. } \\
\text { Slurred speech } \\
\text { Change in mood }\end{array}$ & $\begin{array}{l}0 \\
0 \\
0 \\
0\end{array}$ & $\begin{array}{l}0 \\
1 \\
0 \\
0\end{array}$ & $\begin{array}{l}0 \\
2 \\
0 \\
0\end{array}$ & $\begin{array}{l}1 \\
1 \\
0 \\
2\end{array}$ & $\begin{array}{l}1 \\
1 \\
0 \\
1\end{array}$ & $\begin{array}{l}0 \\
0 \\
0 \\
0\end{array}$ & $\begin{array}{l}\mathbf{0} \\
\mathbf{0} \\
\mathbf{0} \\
\mathbf{0}\end{array}$ & $\begin{array}{l}3 \\
6 \\
0 \\
4\end{array}$ \\
\hline & & & & \multicolumn{7}{|c|}{ Barbiturate index } & 13 \\
\hline \multirow[t]{2}{*}{ J. C. } & 59 & $\begin{array}{l}\text { ? Pulmonary } \\
\text { tuberculosis }\end{array}$ & $\begin{array}{l}\text { Nystagmus } \\
\text { 2-pt. discrim. } \\
\text { Slurred speech } \\
\text { Change in mood }\end{array}$ & $\begin{array}{l}0 \\
0 \\
0 \\
0\end{array}$ & $\begin{array}{l}1 \\
0 \\
0 \\
0\end{array}$ & & $\begin{array}{l}2 \\
2 \\
1 \\
3\end{array}$ & $\begin{array}{l}1 \\
0 \\
0 \\
1\end{array}$ & $\begin{array}{l}0 \\
0 \\
0 \\
0\end{array}$ & $\begin{array}{l}0 \\
0 \\
0 \\
0\end{array}$ & $\begin{array}{l}7 \\
4 \\
4 \\
6 \\
-\end{array}$ \\
\hline & & & & \multicolumn{7}{|c|}{ Barbiturate index } & 21 \\
\hline \multirow[t]{2}{*}{ H. B. } & 30 & Anxiety state & $\begin{array}{l}\text { Nystagmus } \\
\text { 2-pt. discrim. } \\
\text { Slurred speech } \\
\text { Change in mood }\end{array}$ & $\begin{array}{l}0 \\
0 \\
0 \\
0\end{array}$ & $\begin{array}{l}1 \\
0 \\
0 \\
0\end{array}$ & & $\begin{array}{l}3 \\
0 \\
1 \\
0\end{array}$ & $\begin{array}{l}1 \\
0 \\
0 \\
0\end{array}$ & $\begin{array}{l}0 \\
0 \\
0 \\
0\end{array}$ & $\begin{array}{l}0 \\
0 \\
0 \\
0\end{array}$ & $\begin{array}{l}7 \\
2 \\
4 \\
2 \\
\end{array}$ \\
\hline & & & & \multicolumn{7}{|c|}{ Barbiturate index } & 15 \\
\hline \multirow[t]{2}{*}{ N.P. } & 76 & $\begin{array}{l}\text { Generalized } \\
\text { arteriosclerosis }\end{array}$ & $\begin{array}{l}\text { Nystagmus } \\
\text { 2-pt. discrim. } \\
\text { Slurred speech } \\
\text { Change in mood }\end{array}$ & $\begin{array}{l}0 \\
0 \\
0 \\
0\end{array}$ & $\begin{array}{l}1 \\
0 \\
0 \\
0\end{array}$ & $\begin{array}{l}2 \\
1 \\
1 \\
3\end{array}$ & $\begin{array}{l}2 \\
1 \\
1 \\
3\end{array}$ & $\begin{array}{l}1 \\
0 \\
0 \\
1\end{array}$ & $\begin{array}{l}0 \\
0 \\
0 \\
0\end{array}$ & $\begin{array}{l}0 \\
0 \\
0 \\
0\end{array}$ & $\begin{array}{l}6 \\
3 \\
3 \\
6\end{array}$ \\
\hline & & & & \multicolumn{7}{|c|}{ Barbiturate index } & 18 \\
\hline \multirow[t]{2}{*}{ A. B. } & 56 & $\begin{array}{l}\text { Hypertensive } \\
\text { cardiovascu- } \\
\text { lar disease }\end{array}$ & $\begin{array}{l}\text { Nystagmus } \\
\text { 2-pt. discrim. } \\
\text { Slurred speech } \\
\text { Change in mood }\end{array}$ & $\begin{array}{l}\mathbf{0} \\
\mathbf{0} \\
\mathbf{0} \\
\mathbf{0}\end{array}$ & $\begin{array}{l}3 \\
0 \\
0 \\
1\end{array}$ & $\begin{array}{l}3 \\
1 \\
3 \\
3\end{array}$ & $\begin{array}{l}3 \\
0 \\
1 \\
1\end{array}$ & $\begin{array}{l}2 \\
0 \\
0 \\
0\end{array}$ & $\begin{array}{l}0 \\
0 \\
0 \\
0\end{array}$ & $\begin{array}{l}0 \\
0 \\
0 \\
0\end{array}$ & $\begin{array}{l}7 \\
2 \\
5 \\
6\end{array}$ \\
\hline & & & & \multicolumn{7}{|c|}{ Barbiturate index } & 20 \\
\hline \multirow[t]{2}{*}{ T.S. } & 32 & Pharyngitis & $\begin{array}{l}\text { Nystagmus } \\
\text { 2-pt. discrim. } \\
\text { Slurred speech } \\
\text { Change in mood }\end{array}$ & $\begin{array}{l}\mathbf{0} \\
0 \\
0 \\
0\end{array}$ & $\begin{array}{l}1 \\
0 \\
0 \\
0\end{array}$ & $\begin{array}{l}3 \\
2 \\
2 \\
2\end{array}$ & $\begin{array}{l}2 \\
1 \\
1 \\
3\end{array}$ & $\begin{array}{l}1 \\
0 \\
0 \\
1\end{array}$ & $\begin{array}{l}\mathbf{0} \\
\mathbf{0} \\
\mathbf{0} \\
\mathbf{0}\end{array}$ & $\begin{array}{l}0 \\
0 \\
0 \\
0\end{array}$ & $\begin{array}{l}7 \\
4 \\
4 \\
6\end{array}$ \\
\hline & & & & \multicolumn{7}{|c|}{ Barbiturate index } & 21 \\
\hline \multirow[t]{2}{*}{ J. E. } & 42 & $\begin{array}{l}\text { Duodenal } \\
\text { ulcer }\end{array}$ & $\begin{array}{l}\text { Nystagmus } \\
\text { 2-pt. discrim. } \\
\text { Slurred speech } \\
\text { Change in mood }\end{array}$ & $\begin{array}{l}\mathbf{0} \\
\mathbf{0} \\
\mathbf{0} \\
\mathbf{0}\end{array}$ & $\begin{array}{l}1 \\
0 \\
0 \\
0\end{array}$ & $\begin{array}{l}3 \\
1 \\
1 \\
1\end{array}$ & $\begin{array}{l}3 \\
0 \\
2 \\
2\end{array}$ & $\begin{array}{l}2 \\
0 \\
1 \\
3\end{array}$ & $\begin{array}{l}\mathbf{0} \\
\mathbf{0} \\
\mathbf{0} \\
\mathbf{0}\end{array}$ & $\begin{array}{l}\mathbf{0} \\
0 \\
0 \\
0\end{array}$ & $\begin{array}{l}7 \\
2 \\
5 \\
6\end{array}$ \\
\hline & & & & \multicolumn{7}{|c|}{ Barbiturate index } & 20 \\
\hline \multirow[t]{2}{*}{ F. C. } & 19 & $\begin{array}{l}\text { Duodenal } \\
\text { ulcer }\end{array}$ & $\begin{array}{l}\text { Nystagmus } \\
\text { 2-pt. discrim. } \\
\text { Slurred speech } \\
\text { Change in mood }\end{array}$ & $\begin{array}{l}\mathbf{0} \\
0 \\
0 \\
0\end{array}$ & $\begin{array}{l}1 \\
0 \\
1 \\
0\end{array}$ & $\begin{array}{l}3 \\
0 \\
1 \\
1\end{array}$ & $\begin{array}{l}0 \\
0 \\
0 \\
0\end{array}$ & $\begin{array}{l}\mathbf{0} \\
\mathbf{0} \\
\mathbf{0} \\
\mathbf{0}\end{array}$ & $\begin{array}{l}0 \\
0 \\
0 \\
0\end{array}$ & $\begin{array}{l}0 \\
0 \\
0 \\
0\end{array}$ & $\begin{array}{l}5 \\
0 \\
3 \\
2\end{array}$ \\
\hline & & & & \multicolumn{7}{|c|}{ Barbiturate index } & 10 \\
\hline
\end{tabular}


TABLE IIIb

The effect of pentobarbital, 100-120 mg. I.V. as a single injection, on 15 patients with liver disease

\begin{tabular}{|c|c|c|c|c|c|c|c|c|c|c|c|}
\hline \multirow[b]{2}{*}{ Pt. } & \multirow[b]{2}{*}{ Age } & \multirow[b]{2}{*}{ Diagnosis } & \multirow[b]{2}{*}{ Test } & \multicolumn{7}{|c|}{ Degree of drug effect -0 to 4} & \multirow{2}{*}{$\begin{array}{c}\text { Sum } \\
\text { of } \\
\text { effect }\end{array}$} \\
\hline & & & & $\begin{array}{l}\text { Dur } \\
\text { 0 }\end{array}$ & $\begin{array}{l}\text { ation } \\
15\end{array}$ & ${ }_{30} \mathrm{dr}$ & $\begin{array}{l}1 \mathrm{~g} \text { eff } \\
45\end{array}$ & ect in & $\min _{75}$ & tes & \\
\hline \multicolumn{12}{|c|}{ Given in $2.0 \mathrm{ml}$. } \\
\hline \multirow[t]{2}{*}{ G. W. } & 72 & $\begin{array}{l}\text { Hemochroma- } \\
\text { tosis } \\
\text { Cirrhosis } \\
\text { Hepatoma }\end{array}$ & $\begin{array}{l}\text { Nystagmus } \\
\text { 2-pt. discrim. } \\
\text { Slurred speech } \\
\text { Change in mood }\end{array}$ & $\begin{array}{l}0 \\
0 \\
0 \\
0\end{array}$ & $\begin{array}{l}2 \\
3 \\
3 \\
2\end{array}$ & $\begin{array}{l}1 \\
2 \\
0 \\
3\end{array}$ & $\begin{array}{l}0 \\
0 \\
0 \\
3\end{array}$ & $\begin{array}{l}\mathbf{0} \\
\mathbf{0} \\
\mathbf{0} \\
\mathbf{3}\end{array}$ & $\begin{array}{l}\mathbf{0} \\
0 \\
0 \\
2\end{array}$ & $\begin{array}{l}0 \\
0 \\
0 \\
1\end{array}$ & $\begin{array}{l}4 \\
5 \\
4 \\
9\end{array}$ \\
\hline & & & & \multicolumn{7}{|c|}{ Barbiturate index } & 22 \\
\hline \multirow[t]{2}{*}{ O. T. } & 47 & $\begin{array}{l}\text { Biliary } \\
\text { cirrhosis }\end{array}$ & $\begin{array}{l}\text { Nystagmus } \\
2 \text {-pt. discrim. } \\
\text { Slurred speech } \\
\text { Change in mood }\end{array}$ & $\begin{array}{l}0 \\
0 \\
0 \\
0\end{array}$ & $\begin{array}{l}2 \\
1 \\
1 \\
2\end{array}$ & $\begin{array}{l}2 \\
1 \\
0 \\
1\end{array}$ & $\begin{array}{l}1 \\
1 \\
0 \\
0\end{array}$ & $\begin{array}{l}\mathbf{0} \\
0 \\
0 \\
0\end{array}$ & $\begin{array}{l}0 \\
0 \\
0 \\
0\end{array}$ & $\begin{array}{l}0 \\
0 \\
0 \\
0\end{array}$ & $\begin{array}{l}5 \\
4 \\
2 \\
4\end{array}$ \\
\hline & & & & \multicolumn{7}{|c|}{ Barbiturate index } & 15 \\
\hline \multirow[t]{3}{*}{ C. $\mathbf{R}$. } & 49 & $\begin{array}{l}\text { Laennec's } \\
\text { cirrhosis }\end{array}$ & $\begin{array}{l}\text { Nystagmus } \\
\text { 2-pt. discrim. } \\
\text { Slurred speech } \\
\text { Change in mood }\end{array}$ & $\begin{array}{l}0 \\
0 \\
0 \\
0\end{array}$ & $\begin{array}{l}1 \\
3 \\
3 \\
1\end{array}$ & $\begin{array}{l}1 \\
2 \\
0 \\
0\end{array}$ & $\begin{array}{l}0 \\
1 \\
0 \\
0\end{array}$ & $\begin{array}{l}0 \\
1 \\
0 \\
0\end{array}$ & $\begin{array}{l}\mathbf{0} \\
\mathbf{0} \\
\mathbf{0} \\
\mathbf{0}\end{array}$ & $\begin{array}{l}0 \\
0 \\
0 \\
0\end{array}$ & $\begin{array}{l}3 \\
7 \\
4 \\
2\end{array}$ \\
\hline & & & & \multicolumn{7}{|c|}{ Barbiturate index } & 16 \\
\hline & & & Given in $120 \mathrm{ml}$ & & & & & & & & \\
\hline \multirow[t]{2}{*}{ J. F. } & 45 & $\begin{array}{l}\text { Laennec's } \\
\text { cirrhosis }\end{array}$ & $\begin{array}{l}\text { Nystagmus } \\
\text { 2-pt. discrim. } \\
\text { Slurred speech } \\
\text { Change in mood }\end{array}$ & $\begin{array}{l}0 \\
0 \\
0 \\
0\end{array}$ & $\begin{array}{l}1 \\
0 \\
1 \\
1\end{array}$ & $\begin{array}{l}2 \\
0 \\
1 \\
2\end{array}$ & $\begin{array}{l}2 \\
0 \\
0 \\
2\end{array}$ & $\begin{array}{l}0 \\
0 \\
0 \\
0\end{array}$ & $\begin{array}{l}0 \\
0 \\
0 \\
0\end{array}$ & $\begin{array}{l}0 \\
0 \\
0 \\
0\end{array}$ & $\begin{array}{l}\mathbf{5} \\
\mathbf{0} \\
\mathbf{3} \\
\mathbf{5}\end{array}$ \\
\hline & & & & \multicolumn{7}{|c|}{ Barbiturate index } & 13 \\
\hline \multirow[t]{2}{*}{ J. L. } & 35 & $\begin{array}{l}\text { Viral } \\
\text { hepatitis }\end{array}$ & $\begin{array}{l}\text { Nystagmus } \\
\text { 2-pt. discrim. } \\
\text { Slurred speech } \\
\text { Change in mood }\end{array}$ & $\begin{array}{l}0 \\
0 \\
0 \\
0\end{array}$ & $\begin{array}{l}0 \\
0 \\
0 \\
0\end{array}$ & $\begin{array}{l}1 \\
0 \\
2 \\
1\end{array}$ & $\begin{array}{l}1 \\
0 \\
2 \\
0\end{array}$ & $\begin{array}{l}0 \\
0 \\
1 \\
0\end{array}$ & $\begin{array}{l}0 \\
0 \\
0 \\
0\end{array}$ & $\begin{array}{l}0 \\
0 \\
0 \\
0\end{array}$ & $\begin{array}{l}3 \\
0 \\
5 \\
2\end{array}$ \\
\hline & & & & \multicolumn{7}{|c|}{ Barbiturate index } & 10 \\
\hline \multirow[t]{2}{*}{ O. H. } & 44 & $\begin{array}{l}\text { Laennec's } \\
\text { cirrhosis }\end{array}$ & $\begin{array}{l}\text { Nystagmus } \\
\text { 2-pt. discrim. } \\
\text { Slurred speech } \\
\text { Change in mood }\end{array}$ & $\begin{array}{l}0 \\
0 \\
0 \\
0\end{array}$ & $\begin{array}{l}1 \\
0 \\
1 \\
1\end{array}$ & $\begin{array}{l}3 \\
1 \\
2 \\
2\end{array}$ & $\begin{array}{l}2 \\
1 \\
1 \\
1\end{array}$ & $\begin{array}{l}1 \\
1 \\
0 \\
0\end{array}$ & $\begin{array}{l}\mathbf{0} \\
\mathbf{0} \\
\mathbf{0} \\
\mathbf{0}\end{array}$ & $\begin{array}{l}\mathbf{0} \\
0 \\
\mathbf{0} \\
\mathbf{0}\end{array}$ & $\begin{array}{l}7 \\
\mathbf{4} \\
\mathbf{5} \\
\mathbf{5}\end{array}$ \\
\hline & & & & \multicolumn{7}{|c|}{ Barbiturate index } & 21 \\
\hline \multirow[t]{2}{*}{ W. W. } & 51 & $\begin{array}{l}\text { Laennec's } \\
\text { cirrhosis }\end{array}$ & $\begin{array}{l}\text { Nystagmus } \\
\text { 2-pt. discrim. } \\
\text { Slurred speech } \\
\text { Change in mood }\end{array}$ & $\begin{array}{l}\mathbf{0} \\
\mathbf{0} \\
\mathbf{0} \\
\mathbf{0}\end{array}$ & $\begin{array}{l}0 \\
0 \\
0 \\
0\end{array}$ & $\begin{array}{l}2 \\
1 \\
2 \\
1\end{array}$ & $\begin{array}{l}1 \\
0 \\
1 \\
2\end{array}$ & $\begin{array}{l}1 \\
0 \\
0 \\
0\end{array}$ & $\begin{array}{l}\mathbf{0} \\
0 \\
0 \\
0\end{array}$ & $\begin{array}{l}\mathbf{0} \\
\mathbf{0} \\
\mathbf{0} \\
\mathbf{0}\end{array}$ & $\begin{array}{l}\mathbf{5} \\
2 \\
4 \\
4\end{array}$ \\
\hline & & & & \multicolumn{7}{|c|}{ Barbiturate index } & 15 \\
\hline \multirow[t]{2}{*}{ C. $\mathbf{S}$. } & 48 & $\begin{array}{l}\text { Laennec's } \\
\text { cirrhosis }\end{array}$ & $\begin{array}{l}\text { Nystagmus } \\
\text { 2-pt. discrim. } \\
\text { Slurred speech } \\
\text { Change in mood }\end{array}$ & $\begin{array}{l}\mathbf{0} \\
\mathbf{0} \\
\mathbf{0} \\
\mathbf{0}\end{array}$ & $\begin{array}{l}0 \\
0 \\
0 \\
0\end{array}$ & $\begin{array}{l}1 \\
1 \\
0 \\
1\end{array}$ & $\begin{array}{l}1 \\
1 \\
0 \\
1\end{array}$ & $\begin{array}{l}\mathbf{0} \\
0 \\
0 \\
0\end{array}$ & $\begin{array}{l}\mathbf{0} \\
\mathbf{0} \\
\mathbf{0} \\
\mathbf{0}\end{array}$ & $\begin{array}{l}\mathbf{0} \\
\mathbf{0} \\
\mathbf{0} \\
\mathbf{0}\end{array}$ & $\begin{array}{l}\mathbf{3} \\
\mathbf{3} \\
\mathbf{0} \\
\mathbf{3}\end{array}$ \\
\hline & & & & \multicolumn{7}{|c|}{ Barbiturate index } & 9 \\
\hline \multirow[t]{2}{*}{ W. W. } & 52 & $\begin{array}{l}\text { Laennec's } \\
\text { cirrhosis }\end{array}$ & $\begin{array}{l}\text { Nystagmus } \\
\text { 2-pt. discrim. } \\
\text { Slurred speech } \\
\text { Change in mood }\end{array}$ & $\begin{array}{l}\mathbf{0} \\
\mathbf{0} \\
\mathbf{0} \\
\mathbf{0}\end{array}$ & $\begin{array}{l}1 \\
1 \\
0 \\
1\end{array}$ & $\begin{array}{l}1 \\
1 \\
1 \\
2\end{array}$ & $\begin{array}{l}0 \\
0 \\
1 \\
1\end{array}$ & $\begin{array}{l}\mathbf{0} \\
\mathbf{0} \\
\mathbf{0} \\
\mathbf{0}\end{array}$ & $\begin{array}{l}\mathbf{0} \\
\mathbf{0} \\
\mathbf{0} \\
\mathbf{0}\end{array}$ & $\begin{array}{l}\mathbf{0} \\
\mathbf{0} \\
\mathbf{0} \\
\mathbf{0}\end{array}$ & $\begin{array}{l}\mathbf{3} \\
\mathbf{3} \\
\mathbf{3} \\
\mathbf{5}\end{array}$ \\
\hline & & & & \multicolumn{7}{|c|}{ Barbiturate index } & 14 \\
\hline
\end{tabular}


TABLE Imb-Continued

\begin{tabular}{|c|c|c|c|c|c|c|c|c|c|c|c|}
\hline \multirow[b]{2}{*}{ Pt. } & \multirow[b]{2}{*}{ Age } & \multirow[b]{2}{*}{ Diagnosis } & \multirow[b]{2}{*}{ Test } & \multicolumn{7}{|c|}{ Degree of drug effect -0 to 4} & \multirow{2}{*}{$\begin{array}{c}\text { Sum } \\
\text { of } \\
\text { effect }\end{array}$} \\
\hline & & & & \multicolumn{7}{|c|}{$\begin{array}{l}\text { Duration of drug effect in minutes } \\
0 \quad 1530 \quad 45 \quad 60 \quad 75 \quad 90\end{array}$} & \\
\hline \multicolumn{12}{|c|}{ Given in $120 \mathrm{ml}$. infusion } \\
\hline \multirow[t]{2}{*}{ H. K. } & 43 & $\begin{array}{l}\text { Laennec's } \\
\text { cirrhosis }\end{array}$ & $\begin{array}{l}\text { Nystagmus } \\
\text { 2-pt. discrim. } \\
\text { Slurred speech } \\
\text { Change in mood }\end{array}$ & $\begin{array}{l}0 \\
0 \\
0 \\
0\end{array}$ & $\begin{array}{l}0 \\
0 \\
0 \\
1\end{array}$ & $\begin{array}{l}2 \\
0 \\
1 \\
2\end{array}$ & $\begin{array}{l}2 \\
0 \\
1 \\
1\end{array}$ & $\begin{array}{l}1 \\
0 \\
0 \\
0\end{array}$ & $\begin{array}{l}0 \\
0 \\
0 \\
0\end{array}$ & $\begin{array}{l}0 \\
0 \\
0 \\
0\end{array}$ & $\begin{array}{l}\mathbf{5} \\
\mathbf{0} \\
\mathbf{3} \\
\mathbf{5}\end{array}$ \\
\hline & & & & \multicolumn{7}{|c|}{ Barbiturate index } & 13 \\
\hline \multirow[t]{2}{*}{ J. H. } & 65 & $\begin{array}{l}\text { Laennec's } \\
\text { cirrhosis }\end{array}$ & $\begin{array}{l}\text { Nystagmus } \\
\text { 2-pt. discrim. } \\
\text { Slurred speech } \\
\text { Change in mood }\end{array}$ & $\begin{array}{l}0 \\
0 \\
0 \\
0\end{array}$ & $\begin{array}{l}1 \\
0 \\
0 \\
0\end{array}$ & $\begin{array}{l}2 \\
1 \\
2 \\
2\end{array}$ & $\begin{array}{l}2 \\
1 \\
2 \\
1\end{array}$ & $\begin{array}{l}1 \\
0 \\
1 \\
1\end{array}$ & $\begin{array}{l}0 \\
0 \\
0 \\
1\end{array}$ & $\begin{array}{l}0 \\
0 \\
0 \\
0\end{array}$ & $\begin{array}{l}6 \\
3 \\
5 \\
6 \\
-\end{array}$ \\
\hline & & & & \multicolumn{7}{|c|}{ Barbiturate index } & 20 \\
\hline \multirow[t]{2}{*}{ J.F. } & 45 & $\begin{array}{l}\text { Laennec's } \\
\text { cirrhosis }\end{array}$ & $\begin{array}{l}\text { Nystagmus } \\
\text { 2-pt. discrim. } \\
\text { Slurred speech } \\
\text { Change in mood }\end{array}$ & $\begin{array}{l}0 \\
0 \\
0 \\
0\end{array}$ & $\begin{array}{l}1 \\
0 \\
0 \\
0\end{array}$ & $\begin{array}{l}2 \\
0 \\
0 \\
1\end{array}$ & $\begin{array}{l}2 \\
0 \\
0 \\
2\end{array}$ & $\begin{array}{l}1 \\
0 \\
0 \\
1\end{array}$ & $\begin{array}{l}0 \\
0 \\
0 \\
0\end{array}$ & $\begin{array}{l}0 \\
0 \\
0 \\
0\end{array}$ & $\begin{array}{l}6 \\
0 \\
0 \\
5 \\
-\end{array}$ \\
\hline & & & & \multicolumn{7}{|c|}{ Barbiturate index } & 11 \\
\hline \multirow[t]{2}{*}{ M. C. } & 46 & $\begin{array}{l}\text { Laennec's } \\
\text { cirrhosis }\end{array}$ & $\begin{array}{l}\text { Nystagmus } \\
\text { 2-pt. discrim. } \\
\text { Slurred speech } \\
\text { Change in mood }\end{array}$ & $\begin{array}{l}0 \\
0 \\
0 \\
0\end{array}$ & $\begin{array}{l}0 \\
0 \\
0 \\
0\end{array}$ & $\begin{array}{l}1 \\
0 \\
1 \\
2\end{array}$ & $\begin{array}{l}2 \\
0 \\
2 \\
1\end{array}$ & $\begin{array}{l}0 \\
0 \\
0 \\
1\end{array}$ & $\begin{array}{l}0 \\
0 \\
0 \\
0\end{array}$ & $\begin{array}{l}0 \\
0 \\
0 \\
0\end{array}$ & $\begin{array}{l}4 \\
0 \\
4 \\
5\end{array}$ \\
\hline & & & & \multicolumn{7}{|c|}{ Barbiturate index } & 13 \\
\hline \multirow[t]{2}{*}{ J. H. } & 65 & $\begin{array}{l}\text { Laennec's } \\
\text { cirrhosis }\end{array}$ & $\begin{array}{l}\text { Nystagmus } \\
\text { 2-pt. discrim. } \\
\text { Slurred speech } \\
\text { Change in mood }\end{array}$ & $\begin{array}{l}0 \\
0 \\
0 \\
0\end{array}$ & $\begin{array}{l}1 \\
0 \\
0 \\
0\end{array}$ & $\begin{array}{l}2 \\
1 \\
2 \\
1\end{array}$ & $\begin{array}{l}1 \\
1 \\
2 \\
1\end{array}$ & $\begin{array}{l}0 \\
0 \\
1 \\
1\end{array}$ & $\begin{array}{l}0 \\
0 \\
0 \\
0\end{array}$ & $\begin{array}{l}0 \\
0 \\
0 \\
0\end{array}$ & $\begin{array}{l}\mathbf{5} \\
3 \\
5 \\
4\end{array}$ \\
\hline & & & & \multicolumn{7}{|c|}{ Barbiturate index } & 17 \\
\hline \multirow[t]{2}{*}{ M. C. } & 36 & $\begin{array}{l}\text { Laennec's } \\
\text { cirrhosis }\end{array}$ & $\begin{array}{l}\text { Nystagmus } \\
\text { 2-pt. discrim. } \\
\text { Slurred speech } \\
\text { Change in mood }\end{array}$ & $\begin{array}{l}0 \\
0 \\
0 \\
0\end{array}$ & $\begin{array}{l}0 \\
0 \\
0 \\
0\end{array}$ & $\begin{array}{l}1 \\
0 \\
1 \\
1\end{array}$ & $\begin{array}{l}1 \\
0 \\
1 \\
1\end{array}$ & $\begin{array}{l}0 \\
0 \\
1 \\
0\end{array}$ & $\begin{array}{l}0 \\
0 \\
0 \\
0\end{array}$ & $\begin{array}{l}0 \\
0 \\
0 \\
0\end{array}$ & $\begin{array}{l}3 \\
0 \\
4 \\
3\end{array}$ \\
\hline & & & & \multicolumn{7}{|c|}{ Barbiturate index } & 10 \\
\hline
\end{tabular}

however, euphoric symptoms tended to subside and drowsiness supervened. The drowsiness, which was of variable intensity, persisted longer than any other barbiturate effect. After two hours, however, all evidences of barbiturate activity disappeared. The subjects felt as they had before barbiturate injection, but two to four hours later a recurrent drowsiness overwhelmed many control subjects as well as patients with liver disease.

When constant infusions of sodium pentobarbital ( 4 to $6 \mathrm{mg}$. per minute for a total of 100 to 180 mg.) were used, each sign of barbiturate activity was checked for time of onset, rate of increase, peak effect attained and disappearance rate after completion of the infusion. A regular pattern of development and subsidence of barbiturate effect was noted and found to correspond with the amount of barbiturate infused. This parallelism between the amount infused and the development of nystagmus, slurred speech and impaired twopoint discrimination supports the reliability of these signs as measures of the clinical response to intravenous barbiturates.

In an effort to quantitate pentobarbital effects and to facilitate the comparison of patient and control groups, an index of barbiturate activity was devised. Each of the four signs used to assess barbiturate activity was expressed numerically by adding its greatest intensity (rated on a scale of 1 to 4) and duration ( 1 unit for each $15 \mathrm{~min}$.). The numbers representing each sign were then added to obtain the over-all index of barbiturate activity. 
TABLE IV

Comparison of pentobarbital effects in control subjects and patients with liver disease

\begin{tabular}{ccc}
\hline & \multicolumn{2}{c}{ Average barbiturate index } \\
\cline { 2 - 3 } Age groups & $\begin{array}{c}\text { Control } \\
\text { subjects }\end{array}$ & $\begin{array}{c}\text { Patients } \\
\text { with liver } \\
\text { disease }\end{array}$ \\
\hline $20-40$ yrs. & 14 & 10 \\
$40-60$ yrs. & 16.6 & 13.9 \\
over 60 yrs. & 20.6 & 19.3 \\
\hline
\end{tabular}

The 28 control subjects on whom all the major signs of barbiturate activity were checked are recorded in Table IIIa, the 15 patients with liver disease in Table IIIb.

The average index of barbiturate activity was calculated for different ages in both the control and patient groups (Table IV). Although individual doses varied from 100 to $120 \mathrm{mg}$., the average amount of barbiturate used in each group was comparable. The data indicate that patients with liver disease are no more affected by pentobarbital than are control subjects, but that increased sensitivity to this drug exists in older people irrespective of their hepatic function.

\section{Liver function tests.}

Serial liver function tests were carried out before and after injection of pentobarbital, two to four tests being performed at 15 to 30 minute intervals for one to two hours following injection. Since the number of different serial tests possible in any one patient is limited, no more than a pilot run was made with tests which were not expected to change suddenly in response to barbiturate administration. The number of serial tests done in patients with liver disease (L) and in control subjects (C) is indicated parenthetically after the name of each test: serum bilirubin (L-21, C-14), bromsulfalein clearance (L-23, C-9), thymol turbidity and flocculation (L-12, C-11), cholinesterase (L-10, C-12) (4), alkaline phosphatase (L-8, C-6) and cephalin cholesterol flocculation (L-5, C-5).

The injection of sodium pentobarbital did not affect results of the above tests. The average change of the serum bilirubin concentration in the patients with liver disease was, for example, only $0.02 \mathrm{mg}$. per $100 \mathrm{ml}$. The cholinesterase activity has been shown to be a sensitive index of hepatic function (5) and has been reported de- pressed after prolonged use of barbiturates (6), but in the acute tests reported here the pre- and post-barbiturate enzyme activity was virtually identical. When constant intravenous infusions of $\mathrm{BSP}$ are given, the rate of removal of this dye from the blood can be expressed as BSP clearance. ${ }^{8}$ This test, which is fairly sensitive to gross changes in hepato-cellular activity or hepatic blood flow, was not affected for one hour after the injection of sodium pentobarbital.

Hepatic venous catheterization was performed successfully in two patients with chronic and three patients with early liver disease. Hepatic blood flow was estimated by the BSP method (7) and arterial-hepatic venous oxygen differences were measured. Intravenous injections of 120 mg. of sodium pentobarbital did not affect these measurements in any obvious manner.

\section{Measurement of pentobarbital in blood.}

Measurement of pentobarbital levels in serum was assayed in the hope of determining the effect of liver disease on these levels. The spectrophotometric method of Walker, Fisher and McHugh (8) was adopted for this purpose. Like other methods depending upon the absorption of ultraviolet light ( 235 to $240 \mathrm{~m} \mu$ ) by barbiturates, this technique is adequate but not entirely satisfactory. A number of interfering substances may appear in the blood, and the possibility that pharmacologically inactive forms of barbiturate may contribute to absorption at $240 \mathrm{~m} \mu$ cannot be excluded.

In preliminary tests, recoveries of pentobarbital in known concentrations of 1 and $2 \mathrm{mg}$. per 100 $\mathrm{ml}$. of serum were satisfactory. Storage of either serum or its protein-free filtrate at ice-box temperatures for three days did not impair this recovery. On the other hand, serum known to be free of barbiturates often gave readings up to 0.3 $\mathrm{mg}$. per $100 \mathrm{ml}$. False readings up to $0.1 \mathrm{mg}$. per $100 \mathrm{ml}$. were obtained even in fasting subjects. When heparin was used, as in the measurement

${ }^{8}$ When an intravenous infusion of BSP is given at such a rate that the serum concentration of dye remains constant, BSP clearance ( $\mathrm{ml}$. per $\mathrm{min}.)=$ rate of BSP infusion in $\mathrm{mg}$. per $\mathrm{min}$. conc. of BSP in serum in $\mathrm{mg}$. per $\mathrm{ml}$.

In healthy young men, BSP clearance averages about 500 ml. per min. 
of hepatic blood flow, satisfactory readings of barbiturate levels could not be obtained.

To compare the rate of disappearance of pentobarbital from the blood of healthy subjects and those with liver disease, serum levels were measured at 1 to 15 minute intervals for one hour after single intravenous doses. In both groups of subjects, erratic and exceedingly low values - usually between 0.2 and $0.4 \mathrm{mg}$. per $100 \mathrm{ml}$.-were obtained, even within 10 minutes of giving 120 mg. intravenously. In view of the satisfactory in vitro recoveries, we could only surmise that pentobarbital leaves the intra-vascular fluid compartment rapidly. This view agrees with the report of Brodie and his associates (9), who used anesthetic doses of pentobarbital in normal subjects, and noted an abrupt drop in plasma pentobarbital levels during the four hours following a single injection of the drug.

Since concentrations of pentobarbital in the serum after injection of clinical doses appeared to be erratic and low, and since measurement of the drug at low levels was invalidated by false readings, a new technique for comparing the rate of pentobarbital removal from the blood of normal subjects and liver patients was necessary. For this reason, constant infusions of sodium pentobarbital were given to seven control subjects and 10 patients with liver disease at the rate of 4 to 6 mg. per minute for 30 minutes. This method

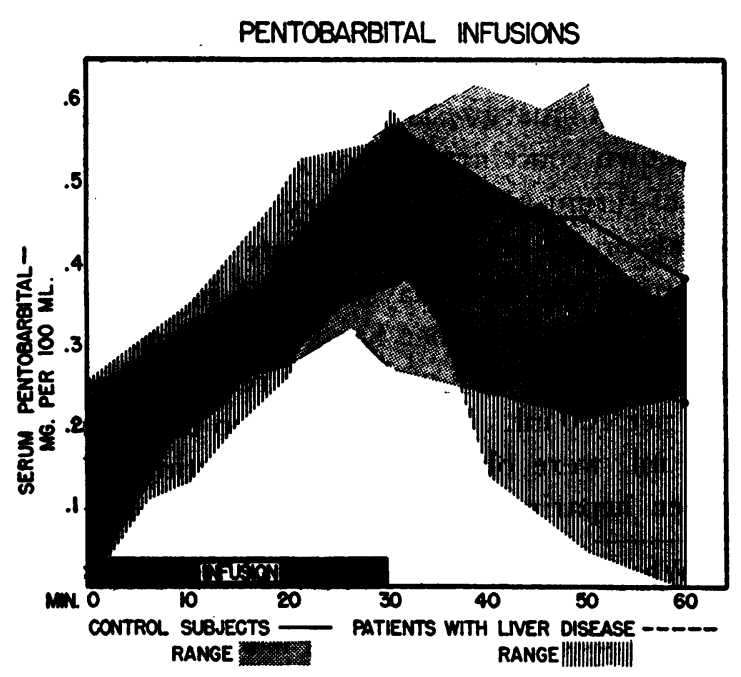

Fig. 1. Serum Pentobarbital Concentrations during ANd after a Constant Infusion of the Drug

The infusion ran from 0 through 30 minutes. provided measurable drug levels in the serum, the amount of interfering substances being determined in blood taken immediately before the barbiturate infusion. The barbiturate levels obtained during the infusion were considered to represent the balance achieved between the infusion rate and removal mechanisms.

As shown in Figure 1, the removal of pentobarbital from the blood proceeded at an equal rate in seven control subjects and 10 patients with severe liver disease. On completion of the barbiturate infusion, pentobarbital blood levels appeared to decrease more rapidly in the liver patients than in control subjects. This may be due in part to rapid diffusion of pentobarbital from blood into ascitic fluid. Four observations made on this point showed pentobarbital levels in blood and ascitic fluid to be similar. Since our results probably reflect both the distribution and metabolism of pentobarbital, their significance is limited. It appears however, that the over-all handling of pentobarbital within one hour of its intravenous administration is not impaired by liver disease.

\section{EFFECTS OF PROLONGED BARBITURATE THERAPY}

Ten males with chronic cirrhosis (Table I) were given barbiturates over a prolonged period of time. Three of these men received the drug twice, making a total of 13 courses. Their ages ranged from 32 to 58 , and all gave histories of alcohol ingestion and poor nutrition over many years. It is noteworthy that all these patients evidenced neurologic or psychologic abnormalities before receiving any barbiturates. Alcoholism rather than hepatic disease probably accounted for the prevalence of insomnia, tremors, nervousness, seizures and peripheral neuritis.

Two patients (three courses) received barbiturate therapy because they required sedation. In these, a pre-therapy baseline study was not possible. The remaining patients were followed for periods of 1 to 12 weeks before barbiturates were given. The total daily doses of pentobarbital were $50 \mathrm{mg}$. in two trials, $100 \mathrm{mg}$. in eight, and $250 \mathrm{mg}$. in one trial. Phenobarbital, 90 and $120 \mathrm{mg}$. daily, was given in two instances. In 12 trials, the drugs were given daily for periods varying from 11 to 41 days. The other trial (Case 1) was stopped after 
five and one-half days because an untoward reaction was suspected.

Daily evaluation of the patient's mental status was made by the same observer, and frequent checks were made with ward physicians, nurses and neighboring patients. In only one case was there any deterioration of the patient's mental status during medication with barbiturates, and, as reported below (Case 1), the attending circumstances were quite complex. During the other 12 courses, the patients either were relieved of their nervous symptoms or, if asymptomatic, evidenced no impairment of their baseline intellectual level.

Since all of the patients suffered from advanced and chronic cirrhosis, obvious physical signs of liver disease persisted throughout their hospital stay. Some signs, such as jaundice and ascites, however, subsided sufficiently that the 10 cases could be discharged as moderately to markedly improved. Excepting the first trial in Case 1, the gradual incline of improvement, as evidenced by the disappearance of jaundice, ascites or both, was not flattened or reversed during the period of barbiturate administration.

Cephalin cholesterol flocculation, bromsulfalein retention, serum bilirubin, prothrombin time, total protein and formol gel reaction were measured every 7 to 10 days. Cholinesterase activity in the serum was determined serially in seven patients. On the whole, the tests reflecting protein metabolism did not change significantly during the period of hospitalization, but serum bilirubin dropped, bromsulfalein retention lessened, or cholinesterase activity increased as the patients grew better. Irrespective of its trend, none of the tests appeared to be affected by the use of barbiturates.

Electroencephalograms were obtained in four patients during barbiturate therapy and were compared with control records obtained before and after the therapy period. Bursts of bilateral, lowvoltage fast activity, of variable duration and more prominent over the frontal lobes, were seen in two of the patients while on pentobarbital. Similar effects have been ascribed to barbiturates in patients without liver disease (10).

Psychological examinations of four of the patients were undertaken by a psychologist. Simple tests of intellectual operations were administered during control periods and during barbiturate ex- hibition. In general the patients performed within normal limits on all the tasks and at all times. Although the smallness of the sample precludes definite conclusions, the tentative impression was gained that test scores obtained were not affected by the intake of barbiturates.

Three of the patients were comatose at one point or another during their hospital stay. Their cases are reported briefly to illustrate two points: (a) when coma occurs in a cirrhotic patient receiving sedation, the responsibility of the sedative is not easily assessed; and (b), patients who suffer hepatic coma because of severe cirrhosis may tolerate pentobarbital once their coma has subsided.

Case 1. A 38-year old male, an alcoholic of long standing, was admitted because of liver disease with marked ascites and peripheral edema. $\mathrm{He}$ improved slowly, but because of an accidental increase in salt intake, a paracentesis yielding $9500 \mathrm{ml}$. was required one month after admission. The day of the tap, his serum sodium was estimated to be $130 \mathrm{mEq}$. per $\mathrm{L}$. as calculated on the basis of serum chloride and bicarbonate values (11). Thirty-six hours later he was put on pentobarbital, $50 \mathrm{mg}$. twice daily. During the next 72 hours it was apparent that the patient was not doing well. $\mathrm{He}$ complained of lassitude, took to his bed, and frequently was found dozing. At this time his estimated serum sodium was $116 \mathrm{mEq}$. per L. Pentobarbital was stopped on the sixth day, but the patient continued to look ill and feel exhausted for another three weeks. Subsequently the patient improved, and two months after the tap received pentobarbital, $50 \mathrm{mg}$. twice daily, for 23 days without ill effect.

Case 2. A 51-year old patient with cirrhosis underwent subtotal gastric resection for pyloric obstruction. Postoperatively jaundice and then ascites appeared requiring paracentesis on the 13th postoperative day. For the next four days the paracentesis wound drained profusely, the patient losing a total of 27 pounds. For 10 days he had received $1.0 \mathrm{Gm}$. chloral hydrate for insomnia, but on the 15th and 16th postoperative nights he required $2.0 \mathrm{Gm}$. The morning of the 17 th day he appeared confused, unresponsive, and very weak; the clinical impression was hepatic coma. His serum sodium, determined by flame photometry, was $110 \mathrm{mEq}$. per $\mathrm{L}$. After hypertonic saline was given, his mental status ameliorated but his serum sodium was no more than $114 \mathrm{mEq}$. per L., and his weakness persisted. Three weeks later, the patient had improved somewhat, the serum sodium being $128 \mathrm{mEq}$. per L. As he still complained of insomnia, he was given pentobarbital, $100 \mathrm{mg}$. at bedtime, which he took for three weeks with relief of symptoms.

Case 3. A 58-year old man with cirrhosis was admitted with ascites. During the first two weeks he was anorectic and lethargic. He slept poorly at night and dozed in the daytime. During this phase he was given $25 \mathrm{mg}$. of 
pentobarbital one morning and slept more than usual that day, although he could always be awakened easily. In the subsequent weeks, the patient improved slowly. One month after admission he received pentobarbital, $50 \mathrm{mg}$. at bed time, for 11 days without difficulty. $\mathrm{He}$ was discharged two months after admission but was readmitted three weeks later because of hematemesis. He was confused and lethargic on admission, and although sedation was not given, his clinical picture changed from one of restless confusion to progressive unresponsiveness. For 48 hours he reacted only to painful stimuli. His hemoglobin fell from 12.4 to $10.4 \mathrm{Gm}$., but the patient was never in shock. After remaining in coma for two days, the patient suddenly recovered and six days later received pentobarbital, $50 \mathrm{mg}$. twice daily, for 14 days without any evidence of depression of consciousness.

Pentobarbital was blamed so readily as being the primary cause of drowsiness and weakness in Case 1 that the possible role of hyponatremia subsequent to paracentesis was ignored. The sequence of events in Case 2, however, lead to re-evaluation of Case 1 with calculation in retrospect of approximate serum sodium values. In both cases the comatose state was preceded by a paracentesis which may have depleted the body's sodium store considerably, particularly since neither patient had peripheral edema to serve as a reservoir of electrolytes (12). Thus hyponatremia as well as the possible bad effects of pentobarbital or chloral hydrate must be weighed as a cause of the mental symptoms in Cases 1 and 2.

In Case 3, a brief but pronounced bout of coma occurred following a moderate hematemesis. The ability of this patient to tolerate the usual sedative dose of pentobarbital within six days of recovery from hepatic coma is noteworthy.

\section{DISCUSSION}

At the beginning of this study, the dangers of administering barbiturates to patients with liver disease loomed so vividly in our minds that doses of 15-30 mg. were used with considerable hesitation. When the expected ill effects failed to materialize, the dose was increased until it appeared that standard hypnotic doses were well tolerated, even by patients with severe cirrhosis. These findings, however, should not be used to justify an indiscriminate exhibition of barbiturate in hepatic disease; rather they may serve as a basis for examining the questions proposed in the introductory paragraphs.
1. Are barbiturates injurious to the liver? Since neither clinical nor biochemical impairment of hepatic function was evident following the use of barbiturates, it appears that the hepatotoxic potentialities of these agents have been overemphasized. The effect of barbiturates on several discrete hepatic functions was not studied, but the broad criterion afforded by the patient's clinical course did not inculpate pentobarbital as harmful to hepatic function.

2. Are barbiturates dangerous to patients with liver disease because hepatic inactivation of these drugs is impaired? In spite of the contradictory evidence obtained by subjecting animals with surgically extirpated or severely damaged livers to barbiturate narcosis, we could find no clinical indications that hypnotic doses of pentobarbital exert a deeper or more prolonged effect in patients with liver disease than in control subjects. Moreover, removal from the blood of barbiturates (or some degradation products) was not grossly different in the two groups. A delayed inactivation of barbiturates by patients with liver disease has therefore not been demonstrated by our studies.

3. Are barbiturates harmful to patients with liver disease because of increased sensitivity of the central nervous system? If the mental faculties of a cirrhotic patient are clouded by the unidentified metabolic factors of incipient hepatic coma, it seems reasonable to assume that the action of any central nervous system depressant will be at least additive. The additional effect of the sedative is, however, hard to assess, for the nervous manifestations of severe liver disease often pass spontaneously from restlessness to coma whether or not sedatives are given. Failure to recognize this natural progression leads to statements that barbiturates are particularly dangerous for the cirrhotic patient with bleeding varices. In these cases, a small dose of barbiturate given during the restless phase is often blamed for the ensuing coma, but this coma is usually the sequel of severe blood loss, not of sedation.

The possibility remains that patients on the verge of coma are actually hypersensitive to sedatives. If this is the case, the hypersensitivity appears to be a transient state conditioned by the metabolic abnormalities of hepatic coma. If hypersensitivity were determined by the structural 
cerebral damage often found in chronic hepatic disorders (13), a constant barbiturate effect might be expected whether or not coma were impending. This does not seem to be the case. For example, the cirrhotic patients whose courses are briefly described tolerated barbiturates very adequately within two months of recovery from comatose states. Furthermore, our liver patients, as a group, were less sensitive to pentobarbital than elderly control subjects.

Current therapeutic practice favors the use of chloral hydrate or paraldehyde for the sedation of hepatic disease, a belief epitomized by Ravdin's enthusiastic statement "chloral hydrate has never been shown to cause hepatic injury" (14). To our knowledge, however, clinical studies showing either that other sedatives (e.g., barbiturates) do harm the liver, or that chloral really is innocuous in human liver disease, do not exist.

Many patients with liver disease do not require sedation. Others who are confused, irrational, or restless require sedation desperately, but barbiturates, and other sedatives as well, may merely intensify the coma which usually succeeds upon the restless phase of liver failure. On the other hand, we suggest that pentobarbital may be used cautiously but without apprehension for allaying such minor nervous symptoms as insomnia, anxiety and tremors in patients with liver disease who do not exhibit the premonitory signs of coma.

\section{SUMMARY}

Pentobarbital in hypnotic doses was given to patients with severe liver disease and to control subjects. The effects of the drug were studied by clinical observations, liver function tests, and measurement of barbiturate blood levels.

No evidence was obtained that patients with liver disease were more sensitive to single injections of pentobarbital, or that the early removal of the drug from the blood of these patients was delayed.

Prolonged administration of pentobarbital to patients with decompensated liver disease did not appear to retard recovery in 12 of 13 trials.

The use of sedatives in patients verging on hepatic coma is not recommended, but the specific dangers ascribed to barbiturates in patients with liver disease appear to have been overemphasized.

\section{ACKNOWLEDGMENTS}

This work was carried out with the technical assistance of Miss Doris Bullard and Miss Elizabeth Johnson.

The authors express their thanks to Dr. Miriam Crowley and Dr. Frederick Wyatt for giving and interpreting the psychological tests, and to Dr. Chaskiel Grossman for aid in interpretation of the electroencephalograms.

\section{REFERENCES}

1. Cameron, G. R., and de Saram, G. S. W., The effect of liver damage on the action of some barbiturates. J. Path. \& Bact., 1939, 48, 49.

2. Scheifley, C. H., and Higgins, G. M., The effect of partial hepatectomy on the action of certain barbiturates and a phenylurea derivative. Am. J. M. Sc., 1940, 200, 264.

3. Koppanyi, T., Dille, J. M., and Linegar, C. R., Studies on barbiturates. XVII. The effect of prolonged chloroform anesthesia on the duration of action of barbiturates. J. Pharmacol. \& Exper. Therap., 1936, 58, 119.

4. Michel, H. O., An electrometric method for the determination of red blood cell and plasma cholinesterase activity. J. Lab. \& Clin. Med., 1949, 34, 1564.

5. Vorhaus, L. J., II, Scudamore, H. H., and Kark, R. M., Measurement of serum cholinesterase activity in the study of diseases of the liver and biliary system. Gastroenterology, 1950, 15, 304.

6. Schütz, F., An effect of barbiturates on serum cholinesterase. J. Physiol., 1943, 102, 259.

7. Bradley, S. E., Ingelfinger, F. J., Bradley, G. P., and Curry, J. J., The estimation of hepatic blood flow in man. J. Clin. Invest., 1945, 24, 890.

8. Walker, J. T., Fisher, R. S., and McHugh, J. J., Quantitative estimation of barbiturates in blood by ultra-violet spectrophotometry. I. Analytical method. Am. J. Clin. Path., 1948, 18, 451.

9. Brodie, B. B., Burns, J. J., Mark, L. C., Lief, P. A., Bernstein, E., and Papper, E. M., The fate of pentobarbital in man and dog and a method for its estimation in biological material. J. Pharmacol. \& Exper. Therap., 1953, 109, 26.

10. Lennox, M., Effects of sedative drugs on the electroencephalogram. Am. J. Psychiat., 1946, 102, 799.

11. Hald, P. M., Heinsen, A. J., and Peters, J. P., The estimation of serum sodium from bicarbonate plus chloride. J. Clin. Invest., 1947, 26, 983.

12. Nelson, W. P., III, Rosenbaum, J. D., and Strauss, M. B., Hyponatremia in portal cirrhosis with ascites. Am. J. Med., 1951, 10, 231.

13. Adams, R. D., and Foley, J. M., The neurological changes in the more common types of severe liver disease. Tr. Am. Neurol. A., 1949, 74, 217.

14. Ravdin, I. S., and Vars, H. M., Further studies on factors influencing liver injury and liver repair. Ann. Surg., 1950, 132, 362. 